\title{
What Customer Wants to Read in Your Proposal
}

\author{
Vijay Kumar SP \\ MBA Strategic Management, M.Sc. Computer Science
}

\section{Abstract}

Earlier sales executives using their interpersonal \& social skills built and cemented relationships with procurement officials over golf games, theatre outings and major events. That era is slowly but surely coming to an end. Today in the digital age, the context is completely different. Every organisation has access to vendors across the globe. Thanks to Artificial Intelligence (AI), organisations can compare their procurement performance in unprecedented detail. Procurement teams have relevant tools and technology to gather insights about seller's product or service offerings to the minutest detail. However, organisations are also under constant pressure to generate value to their stakeholders on quarter-on-quarter basis. Organisations are looking towards sellers to create value to their stakeholders. Sellers should innovate and help organisations grow in multiple dimensions. Empower organisations generate value to their stakeholders. In short become their strategic partner. In this new arrangement, seller-buyer relationship is no more a transactional, order- taking and resource supplying activity. Selling process is transformed with focus on value creation. Value proposition is the core of value creation. Infact it is a disciplined concept. Sellers who use it as strategic asset create win - win situation. This research paper walks through value creation process and details how value propositions are developed.

Keywords: hot buttons, smart framework, value proposition, socratic method, total cost of ownership (TCO), total value of ownership (TVO)

\section{Introduction}

Why do proposals fail to move to the next stage? In business proposals, we often pitch with a brand name, long-standing relationships, and sometimes a technologically superior product at a lower price. Despite this, we often end up on the losing side.

Why does this happen? Primarily because business proposals submitted are not customer focused. While customers wish for competitive pricing, they secretly desire to grow in multiple dimensions such as enhance their customer satisfaction, improve 
their earnings, reduce cost, boost their profitability, better stakeholder management, greater investors wellbeing etc. [Ram Charan (2008)]

Broadly every customer has different needs, requirements, challenges, and aspirations that translate to a combination of metrics. These metrics are called Key Performance Indicators (KPI).

Every procurement a customer makes is stacked against their KPI's, evaluating whether the procurement adds value to their stakeholders or not. In short, proposal evaluators wish and look for superior value for their investments.

Customer focused proposal should not only address customer's KPI's but also focuses on their hidden desires. Value creation is a process of creating and enhancing qualitative and quantitative value to the customer through seller's solution offerings. [ Larry Newman (2016)]

Value propositions in business proposals should provide a concise road map to deliver both aspects in logical and time bound manner. This is precisely what the customer wants to read in a proposal.

Systematic approach to develop and showcase value propositions for different users - economic, technical and end users within the customer's organisation is detailed in this paper. The figure 1 below illustrates our approach.

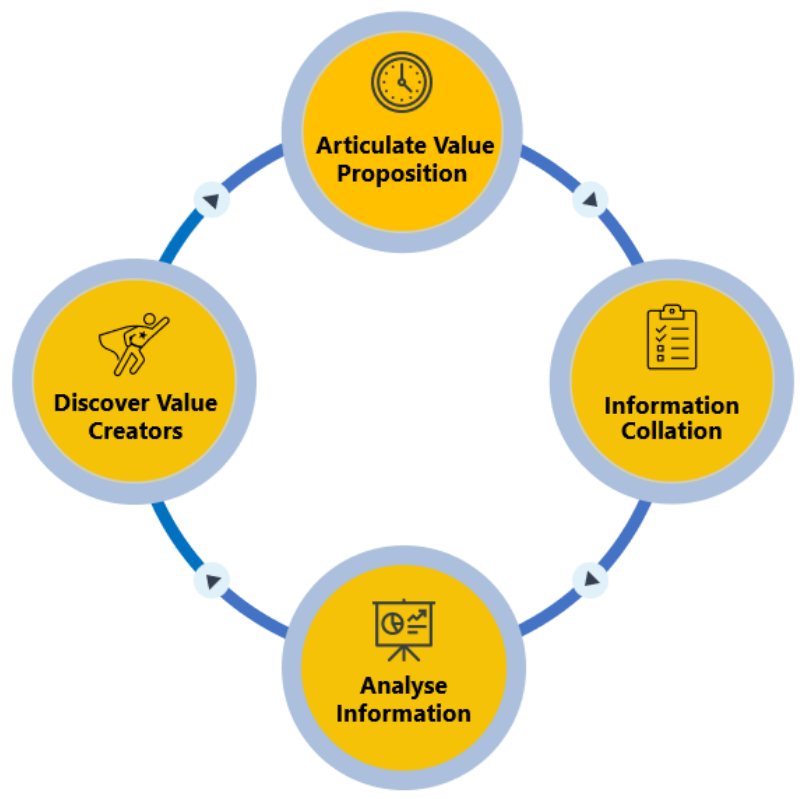

Figure 1: Value Creation Life Cycle: This iterative and radical approach, addresses customer's current and futuristic hot buttons, that sometimes are not even discovered by the customer, into a well-defined unique offering. 


\section{Literature Review}

\section{Collate Quantitative and Qualitative Information of the Customer}

A major challenge of developing value propositions is to identify what to sell, whom to sell and what they really need. To answer all these questions, we need qualitative and quantitative information about the customer. "

Capture a lot of information, both hard facts and impressions. Start with basics like name of the company, business verticals, senior management, headquarters etc.

Once done, work on intellectual aspects of the opportunity like competitive analysis, account research etc.

The more we know about our customer, the better we will be able to identify their concerns. We need both quantity and quality of information to analyse.

However, how do we classify if the information obtained is qualitative?

Customer's opportunities, culture, values, dominant psychology, short-term, medium-term, and long-term goals, customer's customer, customer's competitors, end-customers competitors etc. are classified as qualitative information. [Ram Charan (2008)]

Nevertheless, quality information of a customer is accessible only when the customer trusts you. The easiest way to gain trust from the customer is to truly understand the information they share.

Once we understand, analyse, and dissect this information, it will trigger more questions for the customer which results in more exchange of information and people to people interactions. In no time, this trust will roll into a big snowball.

\section{Identify Hot Buttons through Socratic Method}

Analyse the collated information to identify the customer's requirements, needs and aspirations. The amalgamation of these three facets of the customer is called a "hot button." The figure 2 below provides you with an overview of hot buttons. [ Beveridge /Velton (1982)] 


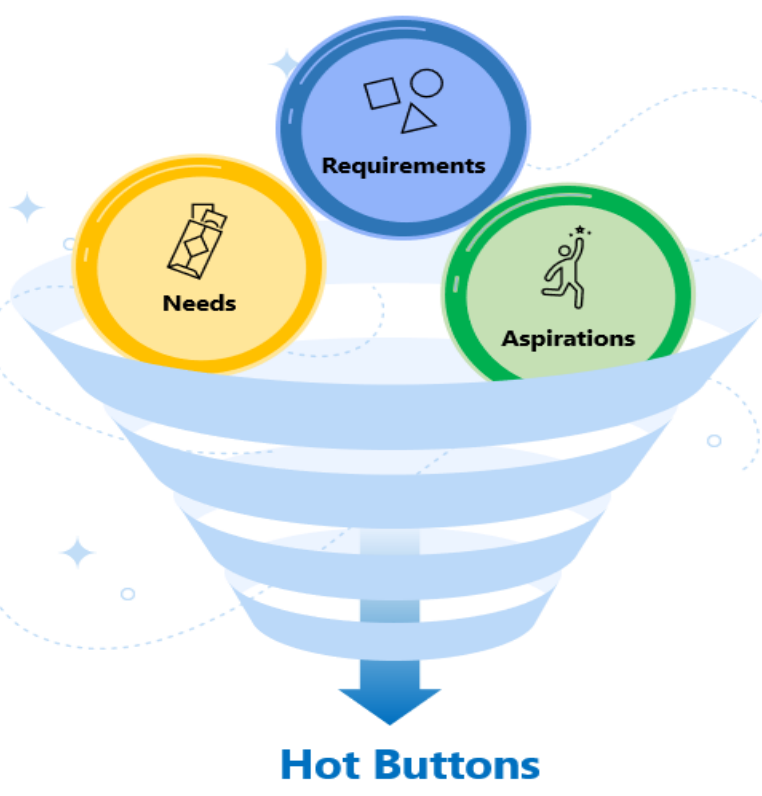

Figure 2: Hot Buttons: No two proposals are alike. Knowing your customer and their hot buttons is the single best discriminator. We need to connect the dots from the customers perspective towards potential sale.

Hot Buttons are of two types implicit and explicit. While explicit hot buttons are relatively easy to find and understand, however implicit hot buttons are always hidden and aspirational. They are vital to examine and comprehend customer's opportunities, desires, and competitive dynamics.

To analyse hot buttons, we will employ the Socratic Method. It is a form of a cooperative argumentative dialogue between individuals, based on asking and answering questions to stimulate critical thinking and to draw out ideas and underlying presupposition [ Larry Newman (2016)]

This is the best approach for analysis of information as it will arouse genuine curiosity about the customer. Participants will solely rely on dialogue.

This methodology is not meant to highlight superiority over our colleagues but to validate the accuracy of the information obtained in the previous phase and to discover customer implicit hot buttons.

Another important trait in this phase is to identify and tap the skills of various internal teams or resources to discover potential hot buttons. For example, Bid Managers and Capture Managers are not expected to understand and dissect financial information like annual reports but this is exactly what we need to do to understand the customer more deeply. 
We need to identify the parameters that are most important to the customer. Is the customer looking for revenue enhancement, growth, expansion, or debt reduction? By analysing customer's annual reports intensely, we can uncover their hidden needs, aspirations, challenges, short-term goals, long-term goals, and sometimes actual relevance to current procurement. [HBR 2020]

For this to happen we need to employ our internal accounts and finance team or business analysis team to skim through customer's annual reports and come up with their analysis.

Once hot buttons are identified, group the related ones, and prioritise the way customer looks at them. If unsure, it works best to ask the customer to validate and prioritise the hot buttons.

This is a very important step in value creation. We need to align with the customers' thought process, their priorities and then work towards a solution.

\section{Develop Value Creators through SMART Framework}

The emphasis in this phase is to solve the customer's hot buttons. Our solutions should always focus on the customers' customers and their problems, motivations, and decision-making process. Interact with different sales teams who have worked with similar clients to identify any learnings. Determine if we need to partner with someone to provide a viable solution to the customer.

Value creators are the soul of value creation. It is a comprehensive sellers solution offering, that broadly addresses customers hot buttons in a methodical framework. Usually, value creators are laced with buyer's benefits and seller's discriminators. [David G. Pugh and Terry R Bacon (2006)]

Value creators should be developed in the Specific, Measurable, Achievable, Result and Timed (SMART) framework. Figure 3 below illustrates value proposition development for easy reference.

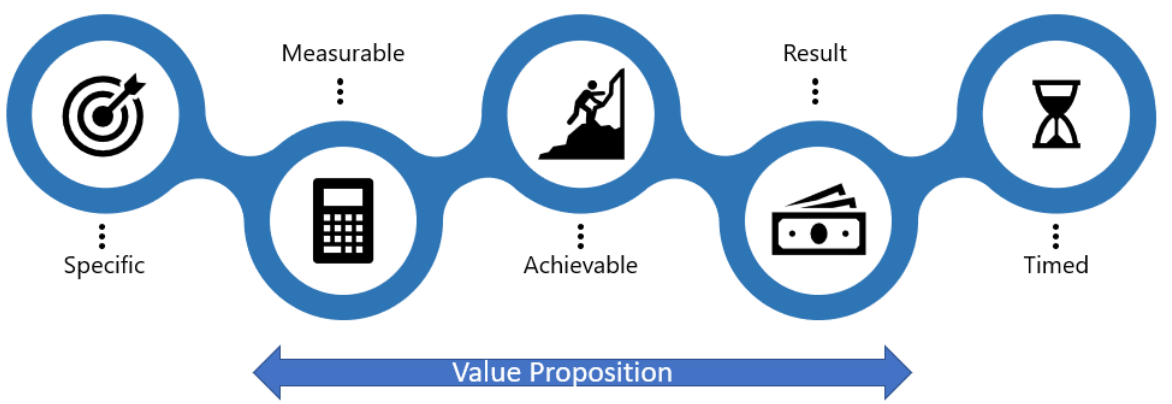


Figure 3: SMART Framework: Value creators should be developed in the SMART Framework. It should highlight quantifiable business benefit, cost and time involved, payback period, relevant proof, and result measurement. Impactful value propositions are often the difference between an ordinary and a winning proposal.

SMART framework is detailed below. All value creators should have the following characteristics:

Specific: Specify the value to be created. Indicate the cost, resources and time involved.

Measurable: Specify how results will be measured and tracked.

Achievable: Value creators should be realistic and achievable. Provide adequate reasoning or cite similar experience.

Result: Quantify the business impact/improvement.

Timed: State the payback period of the benefits.

However, value is perceived differently by different users within an organisation. Hence it is important to develop unique value propositions for different users and address their concerns.

For example, procurement and legal departments (technical buyers) perspective will be different from the marketing perspective. Similarly, end user's perception of value propositions will be different from that of executive management (economic buyers).

Once value creators are formulated for different stakeholders within the customer's organisation, we need to build a roadmap for these value creators with relevance to short, medium, and long terms. The greatest opportunities and mutual growth lie in medium and long terms.

Showcase and discuss these value creators with the customer to gather their inputs and identify any alternatives. If possible, have a pilot implementation - Proof of Concept.

Engage with different and more importantly prominent buyers in the customer's organisation. These isolated testing often helps us to refine our value creators. Study the impact of the value creators on the customer's customer.

Pricing and costing discussions should commence in parallel to ensure our offerings are within the buying range of the customer. The challenge is to position our offerings in the higher end of the customer's buying range.

If the solution is right, we can break away from traditional cost-plus pricing and charge premium price- value price. Value pricing is the customer's perception of the total value derived from our offering. 


\section{Articulate Value Propositions: Showcase Total Cost of Ownership (TCO) vs. Total Value of Ownership (TVO)}

In this digital age, how we read and write has transformed remarkably. Certain Clevel executives can be speed readers and might read the executive summaries on the go and in intervals. Hence information in snippets is preferred and is easily grasped.

In this context, articulating value propositions is a crucial step in this entire process. Value creators developed in the SMART framework should also be written in the SMART framework. It should be simple, clear, and concise. Carefully state all the assumptions and any conditions.

Value propositions is a concise result-oriented action plan to implement value creators. Value proposition should clearly quantify business improvement within the specified period, investment required and how results are measured and tracked.

Relay value propositions throughout the proposal through theme statements, callout boxes, figures, and action captions. Organise executive summaries and section introductions with value propositions for maximum mileage.

Use the Shipley's four-box template to organise your content in the executive summary. Highlight the value proposition for each hot button. For value propositions which cannot be quantified, provide adequate proof of your capabilities and/or highlight your experience. [Larry Newman (2016)]

It would be a clever idea to provide a detailed action plan and process involved for these intangible values in the body of the proposal or in the appendix section of the proposal. Refer to these sections in the executive summary to ensure authenticity.

Focus on all the buyers equally. However, summarise the value propositions for the economic buyers. Stack Total Cost of Ownership (TCO) against Total Value of Ownership (TVO).

Total Cost of Ownership (TCO) is the cost involved in the purchase of a particular asset/benefit, plus operating costs over the asset/benefit's lifespan. Total Value of Ownership (TVO), which is the approximate estimate of the quantified benefits the customer and customer's customer stand to gain. 
Figure below illustrates TCO vs TVO [ Ram Charan (2008)]

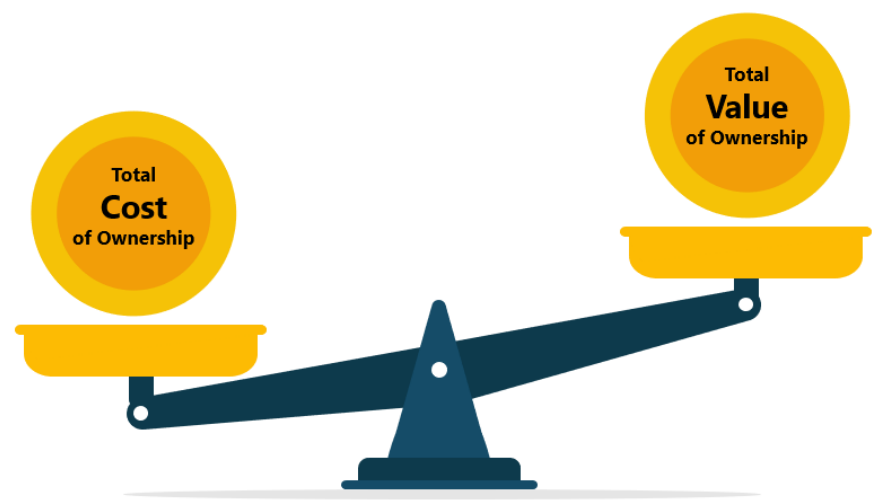

Figure 4: TCO vs TVO: Stack Total Cost of Ownership (TCO) against Total Value of Ownership (TVO). Highlight what the customer stands to lose if they are not opting for our product/service. In Innovation driven industries like Information Technology, customers who buy on price but not on value will fall back and will be at competitive disadvantage.

\section{Methodology}

The purpose of this research paper is to investigate how sellers, proposal professionals and marketers are developing compelling value propositions to their customers. Total of 5 participants were chosen for this experiment in past one year from different industry verticals including IT, ITES, Retail and their customers and prospects belonged to varied sectors including Automobile, Banking, Insurance and Engineering Services.

The data collection method is in-depth interviews to ensure data collection. Their perception and thought process for creating value propositions for their prospects/customers through this prescribed framework is recorded. Twelve semi structured interviews were conducted with these participants to collect the rich information of their experiences while using this proposed framework.

To ensure confidentiality, participants personal details are withheld. However below table illustrates participants industries, their prospect/customer industries, participants role and opportunity status of the opportunities where prescribed value proposition framework was implemented. 
Table 1 : Value Proposition Survey - Implementation of Proposed SMART Framework

\begin{tabular}{|c|c|c|c|c|}
\hline $\begin{array}{l}\text { Participants } \\
\text { Organization }\end{array}$ & $\begin{array}{l}\text { Participant } \\
\text { Industry }\end{array}$ & $\begin{array}{l}\text { Participant } \\
\text { Customer }\end{array}$ & Participant Role & Opportunity Status \\
\hline Participant 1 & $\begin{array}{l}\text { Information } \\
\text { Technology (IT) }\end{array}$ & Banking & Proposal Manager & $\begin{array}{l}\text { Win - Participant } \\
\text { has moved to next } \\
\text { level of Sales } \\
\text { Process (RFP) }\end{array}$ \\
\hline Participant 2 & $\begin{array}{l}\text { Automobile } \\
\text { Industry }\end{array}$ & End User & Sales Manager & $\begin{array}{l}\text { Consistently } \\
\text { achieved revenue } \\
\text { targets by } 153 \%\end{array}$ \\
\hline Participant 3 & $\begin{array}{l}\text { Information } \\
\text { Technology } \\
\text { Enabled Services } \\
\text { (ITES) }\end{array}$ & Automobile Industry & $\begin{array}{l}\text { Senior Sales } \\
\text { Manager }\end{array}$ & $\begin{array}{l}\text { Win -Participant } \\
\text { has won an L1, L2 } \\
\text { support contract } \\
\text { worth USD } \\
250,000 \text { for period } \\
\text { of one } 2 \text { years }\end{array}$ \\
\hline Participant 4 & $\begin{array}{l}\text { Information } \\
\text { Technology (IT) }\end{array}$ & $\begin{array}{l}\text { Engineering } \\
\text { Services }\end{array}$ & $\begin{array}{l}\text { Program Manager, } \\
\text { Proposal Services }\end{array}$ & $\begin{array}{l}\text { Win - Participant } \\
\text { has moved to next } \\
\text { level of Sales } \\
\text { Process (RFP) }\end{array}$ \\
\hline Participant 5 & $\begin{array}{l}\text { Information } \\
\text { Technology } \\
\text { Enabled Services } \\
\text { Industry (ITES) }\end{array}$ & Insurance & $\begin{array}{l}\text { Senior Sales } \\
\text { Manager }\end{array}$ & $\begin{array}{l}\text { On hold. Status } \\
\text { Quo is maintained. }\end{array}$ \\
\hline
\end{tabular}

\section{Empirical Findings \& Analysis}

All the participants were of the view that promoting value propositions is challenging, both internally and to the customer. Just as value proposition needs to be customised for different users in the customer organisation, proposal owners need to have a different plan of action to get different departments internally aligned onboard.

Participant 1 felt that biggest challenge that a sales team in their organisation faces is to build credibility with other departments such as operations, legal, finance and marketing departments. In the past, the sales team have often committed to unrealistic promises to the customer and thrown the problems to other departments like delivery teams to resolve.

Participant 2 was of the view that we should approach the customer, not to sell but to build rapport, develop trust and learn more about their aspirations and hidden desires.

Participant 3 stated that their team (sales team) made lot of effort to convince their internal legal team for the concessions it was offering to prospect for that opportunity.

Participant 4 mentioned that, based on the value propositions developed, there was an exception made on prospect payment terms for that opportunity. Sales team had 
sorted out pricing related sources of friction with legal and finance departments before submitting formal proposal to the customer. Participant 4 is of the view that compliant and responsive proposals are winning proposals.

Participant 5 has indicated that customer has rejected their value propositions as there were sceptical, due to their previous experiences. It is important to develop trust with the customer. Participant has identified a friendly collaborator within the customer organisation to develop value creators for their department. They plan to implement a proof of concept and co-author value propositions with these friendly collaborators to gain their trust.

\section{Conclusion}

The purpose of this research was to develop an comprehensive and compelling methodology and framework for identifying and articulating value propositions. This framework has been efficiently used by the five (5) participants across different industries over period of one year for various opportunities. Twelve semi structured interviews were conducted with these participants to collect the rich information of their experiences while using this proposed framework. Participants feel that proposals laced with unique value propositions for the customer are usually winning proposals.

Value creation method discussed in this research paper will nurture trust and will enable more and more comprehensive interactions with the customer, elevating the relationship to a strategic partnership. Unlike earlier approaches, where buyer and seller relationships are merely transactional.

Well-defined value propositions can destroy competition and ensure better pricing and margins. However, value creation cannot be achieved in silos. A top-down, insideout approach works best.

The entire organisation should embrace value creation and should start submitting proposals centred around value propositions."

Top management should play a key role in this monumental shift and should be involved in training key personnel in developing and articulating value propositions to their major customers.

Outside trainers can play supplemental roles in industry-relevant training and finetuning value propositions.

In conclusion, value propositions highlight superior value for the customer's investments. This is precisely what the customer wants to read in a proposal. 


\section{References}

[1] Michael E Porter (2004) -Competitive Advantage

[2] Larry Bossidy \& Ram Charan (2011) - Execution

[3] Beveridge /Velton (1982) - Positioning to Win

[4] David G. Pugh and Terry R Bacon (2006) - Powerful Proposals

[5] Larry Newman (2016) - Shipley Proposal Guide 4.1

[6] Larry Newman (2014) - Shipley Capture Guide 3.0

[7] Brain Brim (2011) - Strengths based Selling

[8] Jason Harris (2021)- The Soulful art of Persuasion

[9] Ram Charan (2008) - What Customer wants you to Know

[10] Harvard Business School Press (2006)- Written Communication that informs and Influence

[11] Emrah Yayici (2016) - Design Thinking Methodology by (Kindle Edition)

[12] Harvard Business Review (2020)- 10 Must Reads on Design Thinking

[13] Don Norman (2013) - The Design of Everyday Things

[14] Alexander Osterwalder, Yves Pigneur (2014) - Value Proposition DesignHow to Create Products and Services Customers Want

[15] Ram Charan (2021) -Rethinking Competitive Advantage - New rules for the digital age by (Kindle Edition)

[16] Denzin, N. K. \& Lincoln, Y. S. (2005). The SAGE Handbook of Qualitative Research. Thousand Oaks, California: SAGE Publications 3rd ed. 